\title{
Testosterone induced apoptosis in colon cancer cells is regulated by $\mathrm{PI} 3 \mathrm{~K} / \mathrm{Rac} 1$ signaling
}

\begin{abstract}
Saad Alkahtani
Recently, it has been reported that testosterone membrane signaling regulates actin reorganization and induces pro-apoptotic responses in colon tumor cells. In the present study the membrane androgen receptors (mARs)-induced activation of Rac 1 GTPase and the involvement of PI3K/Rac1 signaling in controlling the apoptotic responses in testosterone treated Caco2 colon cancer cells has been analyzed. In line with previous findings, activation of mAR by testosterone conjugates triggered early and transient actin reorganization as indicated by the significant decrease of the G/Total actin ratio after 15- and 30-min treatment of the cells. Interestingly, stimulation of mAR rapidly activated the Rac1 GTPase. This effect was evident after 15 min and persisted for at least $24 \mathrm{~h}$. Testosterone induced Rac 1 activation was fully blocked in Caco2 cells pre-treated with the PI3K inhibitor wortmannin, indicating that Rac 1 signaling is acting downstream of the PI3K pathway. Remarkably, when cells were pre-treated with wortmannin that blocks the PI3K/Rac1 signaling, apoptotic response was almost fully inhibited. These finding suggest that Rac1 activation, triggering actin redistribution, is involved in testosterone induced pro-apoptotic responses governed by mAR activation and emphasize the regulatory role of PI3K/Rac1 signaling in colon tumors.
\end{abstract}

Asian Journal of Andrology (2013) 15, 831-834; doi:10.1038/aja.2013.68; published online 17 June 2013

Keywords: actin; apoptosis; colon cancer cell; testosterone

\section{INTRODUCTION}

Colon, as well as prostate and breast cancer critically, depends on steroid hormones, which participate in auto/paracrine regulation of proliferation, invasiveness and apoptosis of tumor cells. Current evidence indicates the existence of two types of steroid actions: (i) genomic signaling through the classical intracellular receptors; and (ii) non-genomic signaling through still unknown membrane receptors manifesting within minutes. ${ }^{1}$

Functional membrane androgen binding sites have been previously identified and characterized in human prostate and breast cancer cells. ${ }^{2-7}$ Activation of these binding sites by no permeable testosterone albumin conjugates (TACs), was shown to induce strong proapoptotic and anti-tumorigenic effects on various tumors both in vitro and in vivo. ${ }^{2,6,8,9}$ The molecular mechanisms governing these effects have been elucidated and specific signaling cascades triggered by the stimulation of membrane androgen receptors (mARs) have been described in prostate and breast tumor cells. ${ }^{4,5,9-11}$ Functional membrane androgen binding sites have been also reported in colon cancer cells and tissues. ${ }^{12,13}$ Their activation by testosterone conjugates induced potent pro-apoptotic responses. ${ }^{12}$ and inhibition of the migration potential. ${ }^{13,14}$ Moreover, experimental evidence was provided indicating that both, the pro-apoptotic steroid action and the inhibition of the migration potential were independent of the classical androgen receptors signaling. ${ }^{12-14}$ Interestingly, it was further reported that these effects were regulated by a mechanism involving actin reorganization. ${ }^{13,14}$
In a recent study, we have described the signaling pathway governing the mAR-induced effects on actin restructuring in colon tumor cells. ${ }^{15}$ This pathway involves rapid activation of FAK, mTOR, p70S6K and the actin regulating protein PAK1. Interestingly, experiments using specific inhibitors indicated that the Rho/ROCK signaling may not be involved in colon tumor cells, although this pathway was activated in prostate cancer cells. ${ }^{6}$ However, the potential involvement of other small GTPases — such as Racl—in the mAR induced cell responses has not been addressed so far. Since Racl has been implicated in mAR signaling in prostate and breast tumor cells, ${ }^{4,5}$ the present study addressed the role of Racl in colon tumor mAR signaling. In addition, the apoptotic responses of testosterone conjugates in relation to the PI3K/Racl were analyzed. The results presented here imply that Racl activation, triggering actin redistribution, is involved in testosterone induced pro-apoptotic responses governed by mAR activation.

\section{MATERIALS AND METHODS}

\section{Cell cultures}

The Caco2 human colon cancer cell line was obtained from the American Type Culture Collection (Manassas, VA, USA) and were studied between passages 55 and 70 . Based on previous titration experiments ${ }^{12}$ we have used a $10^{-7} \mathrm{moll}^{-1}$ testosterone-HSA concentration for mAR stimulation throughout this study. Caco2 human colon cancer cells are cultured in DMEM (Invitrogen Biochrom KG, Berlin, Germany) supplemented with $25 \mathrm{mmol}^{-1}$ HEPES, $4.5 \mathrm{~g} \mathrm{l}^{-1}$ 
glucose, $L$-glutamin, $10 \%$ fetal bovine serum (Biochrom KG) and $1 \%$ antibiotics.

\section{Preparation of steroid solution}

Before each experiment testosterone-3-(O-carboxymethyl) oximehuman serum albumin, (testosterone-HSA or Testo-HSA) (Sigma, Louis, MO, USA), was dissolved in serum-free culture medium at a final concentration of $10^{-5} \mathrm{moll}^{-1}$. This stock solution was incubated for $30 \mathrm{~min}$ at room temperature with $0.3 \%$ charcoal and $0.03 \%$ dextran, centrifuged at $3000 \mathrm{~g}$ and passed through a $0.45-\mu \mathrm{m}$ filter to remove any potential contamination with free steroid. ${ }^{12}$ Earlier binding studies in prostate and colon cancer cells established the optimal concentration of testosterone-HSA treatments. ${ }^{2,12,16}$ Accordingly, testosterone-HSA solution was used at a final concentration of $10^{-7}$ mol $1^{-1}$ throughout the study. ${ }^{12}$ If not otherwise mentioned, all treatments and incubations with steroids including apoptosis assays were performed in serum-containing medium.

\section{Measurement of G/total actin ratio by Triton X-100 fractionation} For measurement of the Triton X-100 soluble G-actin containing and polymerized Triton X-100 insoluble total-actin (F-actin) containing fractions of cells exposed to testosterone-HSA were prepared as previously described. ${ }^{17-19}$ In brief, $250 \mu$ of Triton-extraction buffer was added $\left(0.3 \%\right.$ Triton X-100, $5 \mathrm{mM}$ Tris, $\mathrm{pH} 7.4,2 \mathrm{mmol} \mathrm{l}^{-1}$ EGTA, $300 \mathrm{mmol} \mathrm{l}^{-1}$ sucrose, $2 \mu \mathrm{mol} \mathrm{l}^{-1}$ phalloidin, $1 \mathrm{mmol} \mathrm{l}^{-1} \mathrm{PMSF}$, $10 \mu \mathrm{g} \mathrm{ml}^{-1}$ leupeptin, $20 \mu \mathrm{g} \mathrm{ml}^{-1}$ aprotinin, $1 \mathrm{mmol} \mathrm{l}^{-1}$ sodium orthovanadate, $50 \mathrm{mmol} \mathrm{l}^{-1} \mathrm{NaF}$ ), and the mixture was incubated for $5 \mathrm{~min}$ on ice. Soluble proteins in the collected supernatants were precipitated with equal volumes of $6 \%$ perochloric acid. The Tritoninsoluble fraction remaining on the plate was precipitated with $500 \mu \mathrm{l}$ of $3 \%$ perochloric acid and collected with scrapping. Samples were centrifuged for $15 \mathrm{~min}$ at $11000 \mathrm{~g}$ and pellets were resuspended in $2 \mathrm{ml}$ $\mathrm{NaOH} 0.1 \mathrm{~mol} \mathrm{l}^{-1}$. Equal volumes of each fraction were subjected to SDS-polyacrylamide gel electrophoresis. A decrease of the triton-soluble (G-) to the total (T-) actin ratio is indicative of actin polymerization.

\section{Rac1 activation assay}

To determine the activity of Racl in testosterone-HSA treated versus untreated cells as well as in cells pre-treated or not with $10^{-6} \mathrm{~mol} \mathrm{l}^{-1}$ wortmannin (Sigma, Darmstadt, Germany) affinity precipitations with Rac reagent (glutathione-S-transferase (GST)-p21-binding domain (PBD) (GST-PBD) from Upstate Biotechnology Inc. (Lake Placid, NY, USA), were performed according to the manufacturer's instructions. Specific protein binds to and precipitates Rac-GTP from cell lysate. Briefly, cells were washed twice in ice-cold TBS and lysed in $\mathrm{Mg}^{2+}$ lysis buffer $\left(25 \mathrm{mmol} \mathrm{l}^{-1}\right.$ HEPES, pH 7.5, $150 \mathrm{mmol}^{-1} \mathrm{NaCl}, 1 \%$ Nonidet P40, $10 \mathrm{mmol}^{-1} \mathrm{MgCl}_{2}, 1 \mathrm{mmol}{ }^{-1}$ EDTA, 10\% glycerol, $25 \mathrm{mmol} \mathrm{l}^{-1}$ $\mathrm{NaF}, 10 \mu \mathrm{g} \mathrm{ml}^{-1}$ aprotinin, $10 \mu \mathrm{g} \mathrm{ml}^{-1}$ leupeptin, $1 \mathrm{mmol} \mathrm{l}^{-1} \mathrm{Na}_{3} \mathrm{VO}_{4}$ ). Cleared cell lysates were incubated with $10 \mu \mathrm{g}$ GST-PBD for $1 \mathrm{~h}$ or with $30 \mu \mathrm{g}$ GST-RBD for $45 \mathrm{~min}$ at $4{ }^{\circ} \mathrm{C}$. A positive control loaded with GTP $\gamma \mathrm{S}$ was included in each assay. Precipitates were washed three times with $\mathrm{Mg}^{2+}$ lysis buffer and suspended in Laemmli's buffer. Samples were subjected to SDS-polyacrylamide gel electrophoresis. Blots were incubated with polyclonal anti-Rac1-antibody (1:200 dilution) (Santa Cruz Biotechnology, Santa Cruz, CA, USA) followed with the appropriate secondary IgG antibody, using the ECL Western blotting kit.

\section{APOPercentage apoptosis assay}

Caco 2 cells (in RPMI 1640, supplemented with $25 \mathrm{mmol} \mathrm{l}^{-1}$ HEPES, $2 \mathrm{mmoll}^{-1} \mathrm{~L}$-glutamine and $10 \%$ fetal bovine serum) were cultured in 96-well plates for the APOPercentage apoptosis assay (Biocolor Ltd, Belfast, Ireland, UK). In the presence or absence of $10^{-6} \mathrm{~mol} \mathrm{l}^{-1}$ wortmannin (Sigma), they were stimulated in serum containing medium with $10^{-7} \mathrm{~mol}^{-1}$ of testosterone-HSA for $12 \mathrm{~h}$. Untreated cells cultured in serum free medium were used as positive control for the apoptotic response.After the indicated time periods, medium was discarded, and apoptosis was assayed using the APOPercentage Apoptosis Assay kit (Biocolor Ltd), as previously described. ${ }^{9}$ The assay uses a dye which is imported by cells undergoing apoptosis, when the 'flip-flop' mechanism translocate phosphatidylserine to the outer membrane leaflet. The dye has a purple-red color. Thereafter, the dye from labeled cells is released in the supplier's buffer and the concentration of intracellular dye is measured at $540 \mathrm{~nm}$ with a reference filter at $620 \mathrm{~nm}$, in anicroplate colorimeter (DynatechMicroElisa Reader, Chantilly, VA, USA).

\section{Statistical analysis}

Data are provided as means \pm s.e.m.; $N$ represents the number of independent experiments. Data were tested for significance using unpaired Student's $t$-test when two-sample means were tested. Differences were considered statistically significant when $P$-values were $<0.05$. All statistical analysis was performed with GraphPadInStat version 3.00 for Windows 95 (GraphPad Software, San Diego, CA, USA, http:// www.graphpad.com).

\section{RESULTS}

In line with previous reports, ${ }^{12}$ activation of mAR by testosterone conjugates triggered early and transient actin reorganization. This was documented by quantitative determinations of the G/Total actin ratio in colon tumor cells treated with $10^{-7} \mathrm{~mol}^{-1} \mathrm{TAC}$ (Figure 1). Indeed, G/Total actin ratio was significantly decreased $(P<0.001)$ after 15- and 30-min treatment of the cells, implying potent actin polymerization upon mAR stimulation.

Since Racl activation has been reported in prostate and breast cancer cells upon mAR stimulation, the involvement of this small GTPase in colon tumors was further evaluated. As shown in Figure 2, stimulation of mAR by TAC rapidly activates the Rac1 GTPase. This effect

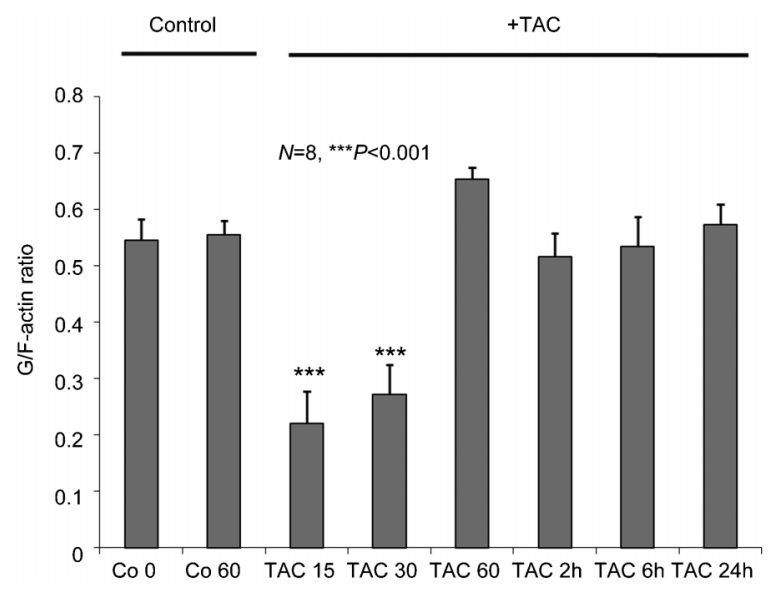

Figure 1 Modulation of the dynamic equilibrium between G- and Total actin in testosterone-HSA stimulated Caco2 cells. Twenty-four hour serum starved cells were stimulated with $10^{-7} \mathrm{~mol}{ }^{-1} \mathrm{TAC}$ for the indicated time points. Total and Gactin were measured by quantitative immunoblot analysis after Triton X-100 subcellular fractionation. Bars present the G/Total actin (mean \pm s.e.) of $n=8$ independent duplicate experiments ( $* * * P<0.001$, compared with control). TAC, testosterone albumin conjugate. 


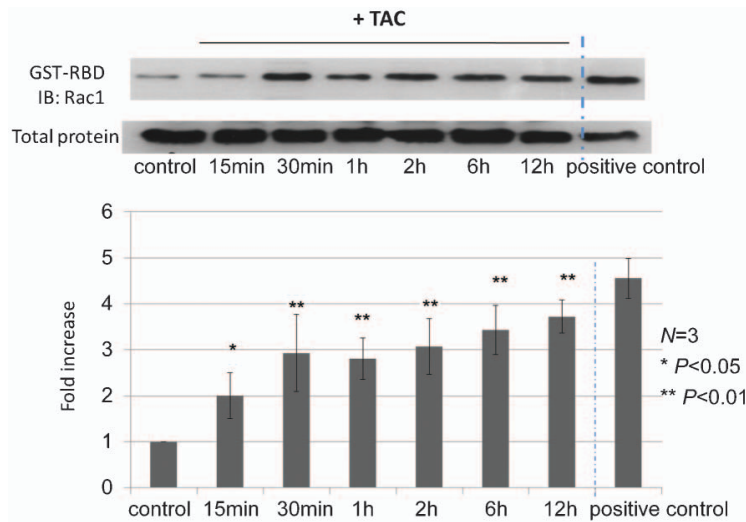

Figure 2 Effects of testosterone-HSA on Rac1 GTPase in Caco2 cells. Caco2 cells were stimulated with $10^{-7} \mathrm{~mol} \mathrm{I}^{-1}$ testosterone-HSA for the indicated time periods. Following cell lysis equal amounts of total lysates were immunoblotted with a specific antibody anti-Racl and total protein. A positive control loaded with GTP $\gamma$ S was included in each assay. Immunoblots were analyzed by densitometry. The intensity of Rac1 GTPase was normalized to the intensity of the corresponding total protein band. Blots are from a representative experiment, whereas the relative fold increases are indicated as mean \pm s.e. from $n=3$ independent experiments of Rac1 GTPase with that of untreated cells $(* P<0.05$, $* * P<0.01)$. TAC, testosterone albumin conjugate.

was evident after $15 \mathrm{~min}$ and persisted for at least $24 \mathrm{~h}$ (Figure 2). This finding indicates that in colon tumor cells Racl small GTPase is induced upon mAR activation and may be implicated both in actin restructuring and the apoptotic responses triggered by testosterone conjugates.

In LNCaP prostate tumor cells, it has been shown that Rac1 GTPase is acting downstream of PI3K and may regulate actin reorganization and apoptotic responses. ${ }^{4}$ Moreover, PI3K is rapidly activated upon testosterone induced mAR stimulation in colon tumor cells. ${ }^{13}$ To further investigate whether Racl is as well acting downstream of $\mathrm{PI} 3 \mathrm{~K}$ in testosterone activated colon tumors, cells were pre-treated with the specific PI3K inhibitor wortmannin followed by stimulation with testosterone conjugates as positive control. As shown in Figure 3, the testosterone induced Racl activation was fully blocked in wortmannin pre-treated $\mathrm{Caco} 2$ cells, implying that Racl signaling is acting downstream of PI3K.

Since the specific PI3K inhibitor wortmannin was shown to block the PI3K/Racl signaling we further analyzed whether this pathway may be implicated in the testosterone-induced apoptotic regression

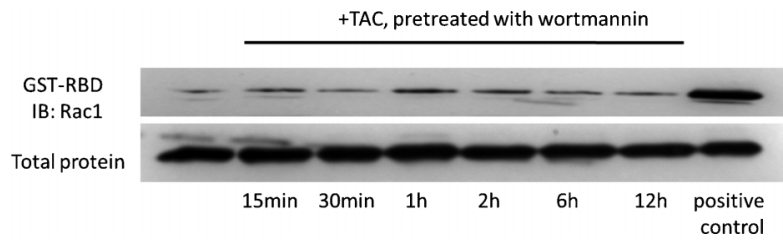

Figure 3 Modulation of the dynamic equilibrium between GST-PBD and total protein in testosterone-HSA-treated $\mathrm{Caco} 2$ cells in the presence or absence of wortmannin. Twenty-four-hour serum-starved cells were stimulated with $10^{-7} \mathrm{~mol}$ $\mathrm{I}^{-1}$ testosterone-HSA in the presence or absence of $10^{-6}$ mol $\mathrm{I}^{-1}$ wortmannin for the indicated time periods. Cellular content of GST-PBD versus total protein was measured by Western blotting using specific antibodies for each in cell lysates. Cells were pre-treated with wortmannin followed by testosterone-HSA stimulation. A positive control loaded with GTP $\gamma S$ was included in each assay. Representative blots from $n=2$ distinct experiments. GST-PBD, glutathione-S-transferase-p21binding domain; TAC, testosterone albumin conjugate. of colon tumor cells. As shown in Figure 4 and in line with previous reports, ${ }^{12}$ treatment of $\mathrm{Caco} 2$ cells by testosterone conjugates significantly $(P<0.01)$ induced potent pro-apoptotic response. Interestingly, when cells were pre-treated with wortmannin that blocks the PI3K/Racl signaling, the apoptotic response was almost fully inhibited. These finding suggest that Racl activation, acting downstream of PI3K and triggering actin redistribution, is mainly involved in the testosterone induced pro-apoptotic responses.

\section{DISCUSSION}

In the present study, it is reported for the first time the involvement of Racl small GTPase in the mAR-induced testosterone responses in Caco 2 colon tumor cells. Indeed, treatment of the cells with testosterone conjugates induced potent actin polymerization and Racl activation that is regulated by PI3K as indicated by control experiments using wortmannin, a specific inhibitor of PI3K. Testosterone-induced rapid Racl/Cdc42 activation has been also reported in the past in both prostate and breast tumor cells. ${ }^{4,5}$ On the other hand, in DU145 prostate cancer cells, Racl activation was not observed, while the involvement of the RhoA/B/ROCK signaling was reported to be crucial for the regulation of actin restructuring and the potent pro-apoptotic response. ${ }^{7}$ These findings further emphasize the central role of the family of small GTPases in regulating actin redistribution triggered by mAR activation in tumors. Interestingly, in a recent study in colon tumor cells, we have shown that Rho/ROCK signaling is not implicated in $\mathrm{mAR}$ signaling. Instead, an alternative pathway was elucidated involving $\mathrm{FAK} / \mathrm{PI} 3 \mathrm{~K} / \mathrm{mTOR} / \mathrm{p} 70 \mathrm{~S} 6 \mathrm{~K} / \mathrm{PAK} 1$ that governs the pronounced actin reorganization. Since the potential role of other Rho family small GTPases such as Racl was not addressed in colon tumors, the analysis of Racl activity upon mAR activation was investigated in the present study.

The data presented here further indicate a significant regulatory role of Racl activation in testosterone induced pro-apoptotic response in colon tumor cells. This hypothesis was strongly supported by control experiments using a specific inhibitor of PI3K. It is known that PI3K is activated in mAR-stimulated colon tumor cells, ${ }^{13}$ while it is well established that Racl is a downstream effector of PI3K governing the organization of actin cytoskeleton. ${ }^{20}$ Interestingly, the findings presented here clearly establish that inhibition of PI3K by wortmannin

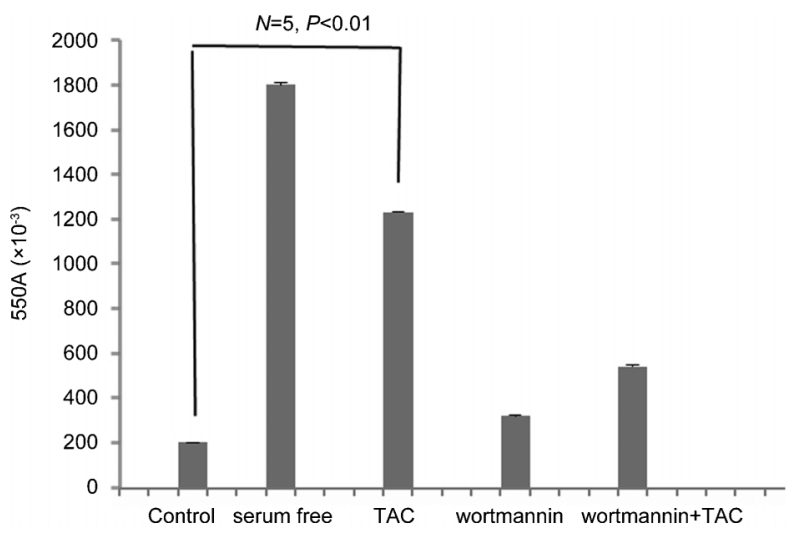

Figure 4 Pro-apoptotic effects of testosterone-HSA in Caco2 cells. Caco2 cells stimulated with $10^{-7} \mathrm{~mol} \mathrm{I}{ }^{-1}$ testosterone conjugate for the indicated time periods. Quantitative APOPercentage apoptosis assay of testosterone-HSA stimulated Caco2 cells according to the manufacturer's instructions. Cells serum starved for comparable periods of time served as a positive control for apoptosis. Bars present the mean optical density (OD) measured at $550 \mathrm{~nm}$ from $n=5$ independent experiments. TAC, testosterone albumin conjugate. 
blocked the apoptotic potential of Caco2 cells, implying a crucial role of the PI3K/Racl signaling in regulating the mAR-induced apoptotic responses. It may also indicate that $\mathrm{mAR}$ activation downregulates other prosurvival effectors, acting downstream of PI3K, such as Akt. Indeed, this has been demonstrated recently in colon tumor cells, implying a mechanism governing the pro-apoptotic potential of mAR. ${ }^{13}$

The recently identified mARs represent a novel category of targets that may participate in apoptotic responses of tumor cells., ${ }^{81,22}$ Various normal and cancer cell lines express functional mAR, including macrophages and T cells, ${ }^{23,24}$ LNCaP cells, ${ }^{4,16,25}$ C6 cells, ${ }^{26}$ MCF7 cells, ${ }^{5}$ T47D cells, ${ }^{27}$ DU145 cells, ${ }^{2,7,9}$ PC12 cells, ${ }^{28}$ VSMC cells ${ }^{29}$ and Caco2 cells. ${ }^{12,13}$ Intensive studies in prostate, breast and colon tumor cells established that mAR trigger rapid, non-genomic signals. These effects are clearly different from those manifested upon activation of the intracellular androgen receptors (iARs) mediating genomic signals. ${ }^{30}$ The mAR-dependent signaling, resulting in profound actin reorganization, was recently characterized in detail in prostate, breast and colon tumor cells. ${ }^{8,15}$ Furthermore, it was shown that mAR activation induced profound apoptotic regression of prostate and colon cancer cells in vitro and in mouse xenograftsin vivo ${ }^{2,6,12,13}$ and suppressed cell growth and motility. ${ }^{5,6,13,14}$ These effects were regulated by the mAR-governed actin reorganization. ${ }^{7,12,13}$ Taken together, these studies clearly established that functional mARs trigger strong antitumorigenic effects, implying a potential role of mAR as a novel target for the development of selective cancer treatments. ${ }^{8}$ The findings presented in the present study further support the significant role of $\mathrm{mAR}$ stimulated PI3K/Rac1 signaling in regulating actin reorganization and the apoptotic response in colon tumor cells. Although the possible involvement of the classical AR (iAR) has not been addressed here, earlier studies in colon tumor cells, using anti androgens or specific siRNA silencing of iAR, have convincingly shown that testosteroneHSA-induced early signaling is not regulated by iAR. ${ }^{12,13}$ In addition, these studies demonstrated that the mAR-induced early actin reorganization the apoptotic response and the migration potential were not influenced by the classical AR. ${ }^{12-14}$ Accordingly, it is assumed that the results presented here are governed by the testosterone-induced $\mathrm{mAR}$ activation.

\section{CONCLUSION}

The results presented here provide clear and significant evidence for the role of actin reorganization and the Racl small GTPase in mARinduced apoptotic responses in colon tumor cells. Stimulation of mAR through TACs induces potent pro-apoptotic responses regulated by PI3K/Racl signaling activation and cytoskeletal rearrangements. These data provide valuable insights into the mechanism of testosterone induced apoptosis in human colon cancer cells.

\section{COMPETING FINANCIAL INTEREST}

The author declares that he has no conflict of interest towards any aspect of the work described in this paper.

\section{ACKNOWLEDGMENTS}

The author extends his appreciation to the Deanship of Scientific Research at King Saud University for funding this study through research group project RGP-VPP-180.

1 Falkenstein F, Norman AW, Wehling W, Clin J. Mannheim classification of nongenomically initiated (rapid) steroid action(s). Endocrinol Metab 2000; 85: 2072-5.
2 Hatzoglou A, Kampa M, Kogia C, Charalampopoulos I, Theodoropoulos PA et al. Membrane androgen receptor activation induces apoptotic regression of human prostate cancer cells in vitro and in vivo. J Clin Endocrinol Metab2005; 90: 893-903. 3 Heinlein CA, Chang C. Androgen receptor in prostate cancer. Endocr Rev 2004; 25 : 276-308.

4 Papakonstanti EA, Kampa M, Castanas E, Stournaras C. A rapid, nongenomic, signaling pathway regulates the actin reorganization induced by activation of membrane testosterone receptors. Mol Endocrinol 2003; 17: 870-81.

5 Kallergi G, Agelaki S, Markomanolaki H, Georgoulias V, Stournaras C. Activation of FAK/PI3K/Rac1 signaling controls actin reorganization and inhibits cell motility in human cancer cells. Cell Physiol Biochem 2007; 20: 977-86.

6 Kampa M, Kogia C, Theodoropoulos PA, Anezinis P, Charalampopoulos I et al. Activation of membrane androgen receptors potentiates the antiproliferative effects of paclitaxel on human prostate cancer cells. Mol Cancer Ther 2006; 5: 1342-51.

7 Papadopoulou N, Charalampopoulos I, Alevizopoulos K, Gravanis A, Stournaras C. Rho/ROCK/actin signaling regulates membrane androgen receptor induced apoptosis in prostate cancer cells. Exp Cell Res 2008; 314: 3162-74.

8 Papadopoulou N, Papakonstanti EA, Kallergi G, Alevizopoulos K, Stournaras C. Membrane androgen receptor activation in prostate and breast tumor cells: molecular signaling and clinical impact. IUBMB Life 2009; 61: 56-61.

9 Papadopoulou N, Charalampopoulos I, Anagnostopoulou V, Konstantinidis G, Föller M et al. Membrane androgen receptor activation triggers down-regulation of PI-3K/Akt/ NF-kappaB activity and induces apoptotic responses via Bad, FasL and caspase- 3 in DU-145 prostate cancer cells. Mol Cancer 2008; 7: 88.

10 Lieberherr M, Grosse B. Androgens increase intracellular calcium concentration and inositol 1,4,5-trisphosphate and diacylglycerol formation via a pertussis toxinsensitive G-protein. J Biol Chem 1994; 269: 7217-23.

11 Sun YH, Gao X, Tang YJ, Xu CL, Wang LH. Androgens induce increases in intracellular calcium via a G protein-coupled receptor in LNCaP prostate cancer cells. J Androl 2006; 27: 671-8.

12 Gu S, Papadopoulou EM, Gehring O, Nasir K, Dimas SK et al. Functional membrane androgen receptors in colon tumors triggers pro-apoptotic responses in vitro and reduce drastically tumor incidence in vivo. Mol Cancer 2009; 8: 114.

13 Gu S, Papadopoulou N, Nasir K, Föller M, Alevizopoulos K et al. Activation of membrane androgen receptors in colon cancer inhibits the prosurvival signals Akt/ Bad in vitro and in vivo and blocks migration via vinculin/actin signaling. Mol Med 2011; 17: 48-58.

14 Schmidt EM, Gu S, Anagnostopoulou V, Alevizopoulos K, Föller M et al. Serum- and glucocorticoid-dependent kinase-1-induced cell migration is dependent on vinculin and regulated by membrane androgen receptor. FEBS J 2012; 279: 1231-42.

15 Gu S, Kounenidakis M, Schmidt EM, Deshpande D, Alkahtani S et al. Rapid activation of FAK/mTOR/p70S6K/PAK1-signaling controls the early testosterone-induced actin reorganization in colon cancer cells. Cell Signal 2013; 25: 66-73.

16 Kampa M, Papakonstanti EA, Hatzoglou A, Stathopoulos EN, Stournaras C et al. The human prostate cancer cell line LNCaP bears functional membrane testosterone receptors that increase PSA secretion and modify actin cytoskeleton. FASEB $J$ 2002; 16: 1429-31.

17 Stournaras C, Stiakaki E, Koukouritaki S, Theodoropoulos PA, Kalmanti M et al. Altered actin polymerization dynamics in various malignant cell types: evidence for differential sensitivity to Cytochalasin B. Biochem Pharmacol1996; 52: 1339-46.

18 Papakonstanti EA, Stournaras C. Actin cytoskeleton architecture and signalling in osmosensing. Methods Enzymol 2007; 428: 227-40.

19 Papakonstanti E, Castanas E, Emmanouel DS, Hartig R, Stournaras C. Early alterations of actin cytoskeleton in OK cells by opioids. J Cell Biochem 1998; 70: 60-9.

20 Vanhaesebroeck B, Alessi DR. The PI3K-PDK1 connection: more than just a road to PKB. Biochem J 2000; 346: 561-76.

21 Michels G, Hoppe UC. Rapid actions of androgens. Front Neuroendocrinol 2008; 29 : 182-98.

22 Kampa M, Pelekanou V, Castanas E. Membrane-initiated steroid action in breast and prostate cancer. Steroids 2008; 73: 953-60.

23 Benten WP, Lieberherr M, Giese G, Wrehlke C, Stamm 0 et al. Functional testosterone receptors in plasma membranes of T cells. FASEB J 1999; 13: 123-33.

24 Benten WP, Lieberherr M, Stamm O, Wrehlke C, Guo Z et al. Testosterone signaling through internalizable surface receptors in androgen receptor-free macrophages. $\mathrm{Mol}$ Biol Cell 1999; 10: 3113-23.

25 Wang Z, Liu L, Hou J, Wen D, Yan C et al. Rapid membrane effect of testosterone in LNCaP cells. Urol Int 2008; 81: 353-9.

26 Gatson JW, Kaur P, Singh M. Dihydrotestosterone differentially modulates the mitogen-activated protein kinase and the phosphoinositide 3-kinase/Akt pathways through the nuclear and novel membrane androgen receptor in $\mathrm{C} 6$ cells. Endocrinology 2006; 147: 2028-34.

27 Kampa M, Nifli AP, Charalampopoulos I, Alexaki VI, Theodoropoulos PA et al. Opposing effects of estradiol- and testosterone-membrane binding sites on T47D breast cancer cell apoptosis. Exp Cell Res 2005; 307: 41-51.

28 Alexaki VI, Charalampopoulos I, Kampa M, Nifli AP, Hatzoglou A et al. Activation of membrane estrogen receptors induce pro-survival kinases. J Steroid Biochem Mol Biol 2006; 98: 97-110.

29 Somjen D, Kohen F, Gayer B, Kulik T, Knoll E et al. Role of putative membrane receptors in the effect of androgens on human vascular cell growth. $J$ Endocrinol 2004; 180: 97-106.

30 Foradori CD, Weiser MJ, Handa RJ. Non-genomic actions of androgens Front Neuroendocrinol2008; 29: 169-81. 